\title{
ORIGINAL
}

\section{Registration of Alpha Tracks in Polycarbonate Foils Using Electrochemical Etching}

\author{
Shian-Jang $\mathrm{Su}^{*}, * 1$ and Chao-Ming TSAI*,*1
}

(Received November 21, 1980)

(Accepted January 23, 1981)

\begin{abstract}
Registration of $\alpha$-tracks and fast-neutron-induced recoil tracks by the electrochemical etching (ECE) technique as applied to sensitive Lexan polycarbonate foils has provided a simple, sensitive, and inexpensive means of neutron dosimetry. The application of this ECE technique to the amplification of alpha particle tracks in $250-\mu \mathrm{m}$-thick Lexan polycarbonate foils was studied here. The intention is to produce permanently stable tracks which are suitable for $\alpha$ particle detection.

The detection efficiency for $\alpha$ particles as a function of etching time under conditions of $1,000 \mathrm{~V}, 2 \mathrm{kHz}$, $22^{\circ} \mathrm{C}$, and $50 \%$ alcoholic $\mathrm{KOH}$ solution was shown. It seems that the track registration efficiency is not proportional to the specific ionization in the polycarbonate foil. From the study on the relative frequency of track diameter distribution it is evident that the track diameter depends only on the latent track position in the foil.
\end{abstract}

KEY WORDS: electrochemical etching, polycarbonate foil, alpha track, track diameter, specific ionization, Bragg curve, bulk layer, latent track position

\section{INTRODUCTION}

In 1958 YounG $^{1)}$ discovered that microscopic pits were formed in the surface of solids which had been irradiated with heavy particles and etched: an important observation which remained unexploited for several years before the study of charged particle registration by preferential etching was taken up again in the early 1960 's. $^{2-4)}$ It was shown that tracks could be made visible in a variety of dielectric materials such as minerals (mica), natural or artificial inorganic glasses, and especially in organic polymers.

FLeISCHER et al. $^{5)}$ showed in their extensive research that tracks could be made visible by chemical agents (etchants) in several dielectrics, but the tracks were small and required tedious microscopic counting. TOMMASINO and ARMELLINI ${ }^{6)}$ proposed an electrochemical etching (ECE) method to enhance visibility of particle tracks in polymers. In

* 蘇献章, 蔡昭明

*1 Health Physics Division, Institute of Nuclear Energy Research; Lung-Tan, Taiwan, Republic of China.

核能研究所保健物理組; 台湾省龍潭, 中華民国 polycarbonate, tracks have been amplified in diameter so as to be made visible to the unaided eye. ${ }^{7,8)}$ Under neutron bombardment fast neutrons produce charged recoil and (n, $\alpha$ ) particle tracks by interacting with the atomic constituents of the polymer. For the neutron dosimetry application, the ECE was shown to be much more promising than chemical etching methods. ${ }^{9,10)}$

Track registration effects by ECE using an alpha standard source are studied to extend this technique in order to measure $\alpha$ particles permanently in the polycarbonate foils.

\section{EXPERIMENTAL}

\section{Electrochemical etching apparatus}

Figure 1 shows the ECE apparatus used in this study. The chamber was constructed from Lucite and designed so that nineteen foils could be etched simultaneously. The equipment consisted of two Lucite cylindrical chambers each having dimensions of $4.5 \mathrm{~cm}$ in length and $16 \mathrm{~cm}$ in diameter. Nineteen foils are placed in the windows between the chambers and each chamber is electrically and hydrostatically isolated by an packing ring having a 1 inch O.D., 5.8 inch I.D., and 3/16 


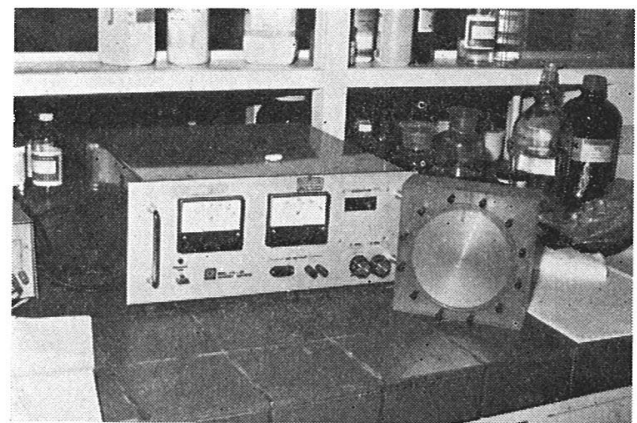

Fig. 1 The electrochemical etching apparatus.

inch thickness.

The two chambers are then held together and bolted tight to insure that they are watertight. A slot was made on the top of each chamber for inserting the stainless steel electrodes. The electrodes are kept parallel to the plane of the foil for good reproducibility.

Etchant solutions were prepared by adding a know amount of potassium hydroxide to a known amount of distilled water in a breaker to get the desired percentage concentration by weight. Ethyl alcohol was added to the above etchant to increase the etching speed. ${ }^{10}$ ) Fifty percent ethyl aocohol per volume in a $45 \% \mathrm{KOH}$ solution $(50 \%$ Alcohol$\mathrm{KOH}$ ) was chosen as the principal etchant in this study. ${ }^{10)}$

The high voltage is generated by an audio generator suppling the input to a push-pull amplifier which furnishes variable output voltages range from 400 to $1,400 \mathrm{~V}$ at variable frequencies of sinusoidal waveform which range from $0.8 \mathrm{kHz}$ to $15 \mathrm{kHz}$. Track efficiencies and background increase with applied voltage to $1,400 \mathrm{~V}$ without reaching a plateau when other parameters are maintained constant. It is obvious that 1,000 volts is chosen as the optimum applied voltage because its high ratio of efficiency to background. ${ }^{10}$

A frequency of $2 \mathrm{kHz}$ seems result in optimum sensitivity. At low frequencies (below $2 \mathrm{kHz}$ ) the number of pounding by the $\mathrm{K}^{+}$or $\mathrm{OH}^{-}$ions to the surface of the polycarbonate foil per unit time is low, which may not be enough to amplify tracks in the deeper layers. At high frequencies, for example at $15 \mathrm{kHz}$, the ions are relatively immobile due to inertial effects and viscosity, therefore, the ions at this frequency would appear to be relatively stationary.

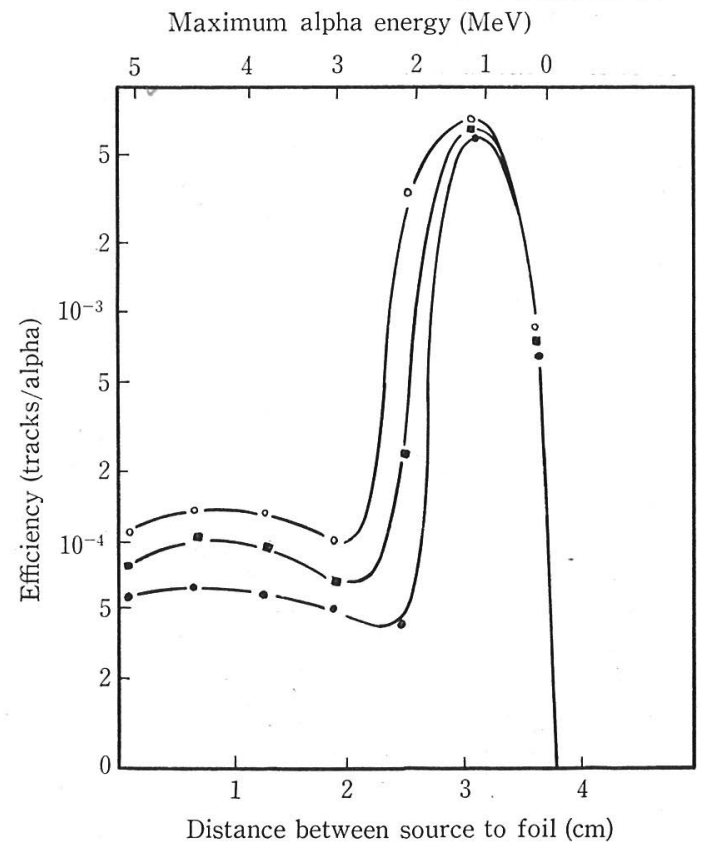

Fig. 2 Alpha particle detection efficiency as a function ${ }^{239} \mathrm{Pu}$ of alpha energy for various etching time under standard etching condition $\left(1,000 \mathrm{~V}, 2 \mathrm{kHz}, 22^{\circ} \mathrm{C}, 50 \%\right.$ alcoholic $\mathrm{KOH}$ solution). $\mathrm{O}, 90 \mathrm{~min} ; \mathbf{\square}, 60 \mathrm{~min}$; $\bullet$, $30 \mathrm{~min}$.

\section{Alpha irradiation}

To examine the efficiency of $\alpha$ track registration, a $2.0 \mu \mathrm{Ci}{ }^{239} \mathrm{Pu}$ source containing also $0.335 \mu \mathrm{Ci}$ of ${ }^{238} \mathrm{Pu}$ was used. Foils were irradiated at different distances from the source to produced alpha particles with energies below $5.15 \mathrm{MeV}$. A surface barrier $\alpha$ spectrometry system was set up to get the $\alpha$ particle flux density $(\alpha$ 's $/ \mathrm{cm} \cdot \mathrm{sec})$ and its maximum peak energy. During the preliminary studies track distributions on the foil were quite inhomegeneous, especially at distances between $2 \mathrm{~cm}$ and $3 \mathrm{~cm}$ in air, so collimators along the path from source to foil with $5 \mathrm{~mm}$ diameter were used during the irradiation to decrease the inhomogeneity. All the $\alpha$ particles impinge on the foil in the normal direction.

\section{Foil reading methods}

Two new counting techniques-microfiche reader and overhead transparency projector were used to facilitate counting of the polycarbonate foils. These two techniques offer several advantages over the conventional microscope for low track density. A filar micrometer was placed on the microscope 


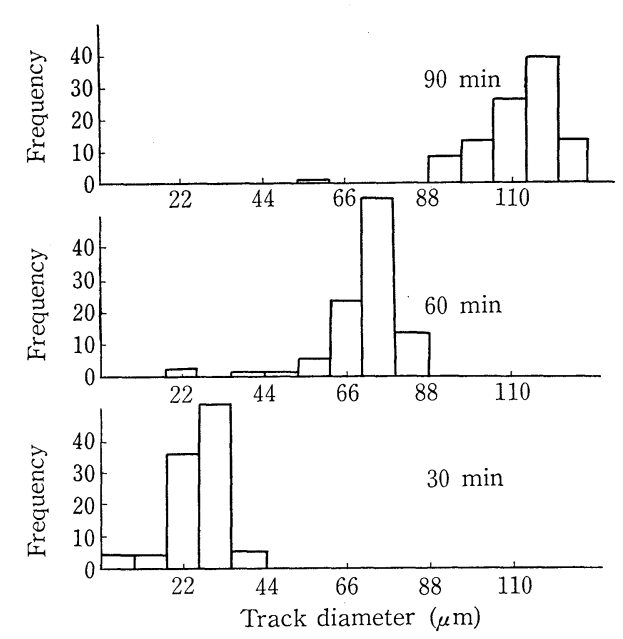

Fig. 3 Relative track diameter distribution of $0.1 \mathrm{MeV}$ alpha particles for different etching times under standard etching condition $\left(1,000 \mathrm{~V}, 2 \mathrm{kHz}, 22^{\circ} \mathrm{C}\right.$, $50 \%$ Alcoholic $\mathrm{KOH}$ Solution).

eyepiece for track diameter measurement. If the track is not a round shape, e.g. elliptic in shape, the average value of the major and minor axes was taken as the track diameter.

\section{RESULTS AND DISCUSSION}

The efficiency of $\alpha$ particle track production as a function of distance between source and foil (or $\alpha$ energy) for different etching times under the standard conditions $\left(1,000 \mathrm{~V}, 2 \mathrm{kHz}, 22^{\circ} \mathrm{C}, 50 \%\right.$ Alcohol$\mathrm{KOH}$ solution) are shown in Fig. 2. From this figure it is seen that there is a maximum track detection efficiency which occurs at a rather low $\alpha$ energy and decreases toward higher energies and is approximately flat above $3 \mathrm{MeV}$ for $\alpha$ particles from this ${ }^{239} \mathrm{Pu}$ source.

In passing through the polycarbonate foil, $\alpha$ particles lose energy chiefly by interaction with electrons and the dissociation or excitation of molecules. The relationship between $\alpha$-energy and specific ionization (ion pairs per $\mathrm{mm}$ ) in polycarbonate foil obviously follows the Bragg curve. When the velocity of the particle has been reduced to a point at which it is comparable to the velocity of the valency electrons in an atom of the polycarbonate material, a new phenomenon becomes important, the particle starts making elastic collisions with the atoms rather than exciting the atomic electrons. The ion-atom collisions give rise to what is known as "nuclear stopping" as compared to the "electronic stopping" which occurs at the higher velocities. It is evident that track registration efficiency is not directly proportional to the specific ionization in the polycarbonate foil. The specific ionization at the peak for low energy $\alpha$ 's is 2 to 3 times higher than that at high energy. But the track efficiencies at low energy increase to 50-100 times higher than those at high energy. The reasons could be 1) the nuclear stopping can cause more main chain rupture or side chain breakage of the polycarbonate foil, or 2) low damage in the polycarbonate foil will tend to repair or recombine, and the probability of recombination for high damage becomes very small. From these postulates the track efficiency increases more rapidly than a single power of $(\mathrm{d} E / \mathrm{d} x)$. The bulk (surface) layer was etched away from the surface of the foil as the etching time increased, so more tracks began to appear from the deeper layers, leading to an increase in the track efficiency with the etching time. The surface layer removed during 90 minutes of etching time is equal to $3.9 \mu \mathrm{m}$. The high specific ionization peak for $2.2 \mathrm{MeV} \alpha$ particles in Lexan polycarbonate foil occurs at a depth of about $3 \mu \mathrm{m}$. It is almost equivalent to the surface layer removed during the 90 minutes of etching. For 30 minutes etching, the high specific ionization peak of $2.2 \mathrm{MeV} \alpha$ particles lies deeper in the foil than the surface layer removed yielding low track registration efficiency. The detection efficiencies of the $2.2 \mathrm{MeV} \alpha$ 's and $1.2 \mathrm{MeV} \alpha$ 's are equal at $90 \mathrm{~min}$ but for the $3 \mathrm{MeV} \alpha$ 's, will jump suddenly as the etching time continues to increases above $90 \mathrm{~min}$. This causes the high efficiency peak to broaden as the etching time increases.

To check this explanation in more detail, relative frequencies (expressed in percent) of track diameter distributions of $0.1 \mathrm{MeV}, 2.2 \mathrm{MeV}$, and $5.05 \mathrm{MeV}$ $\alpha$ particles for different etching times under standard etching conditions were plotted as histograms. For very low energy $\alpha$ 's (Fig. 3) most of the latent tracks occur in the outside layer of the polycarbonate foil. So no more small tracks are observed, and the track increases its diameter with etching time and $90 \%$ of the tracks occur with diameters that lie between 88 to $132 \mu \mathrm{m}$ for 90 minutes of etching time. In Fig. 4, clusters of tiny tracks were observed for 60 and 90 minutes of etching time. This probably means that after 60 

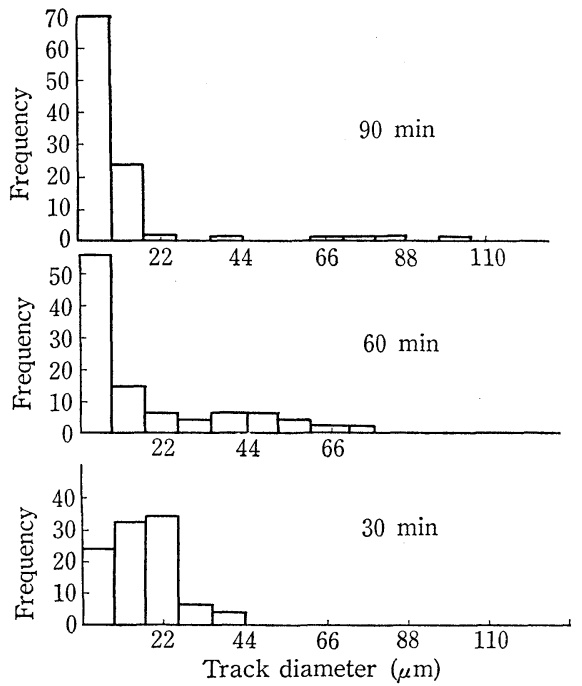

Fig. 4 Relative track diameter distribution of $2.2 \mathrm{MeV}$ alpha particles for different etching times under standard etching condition.
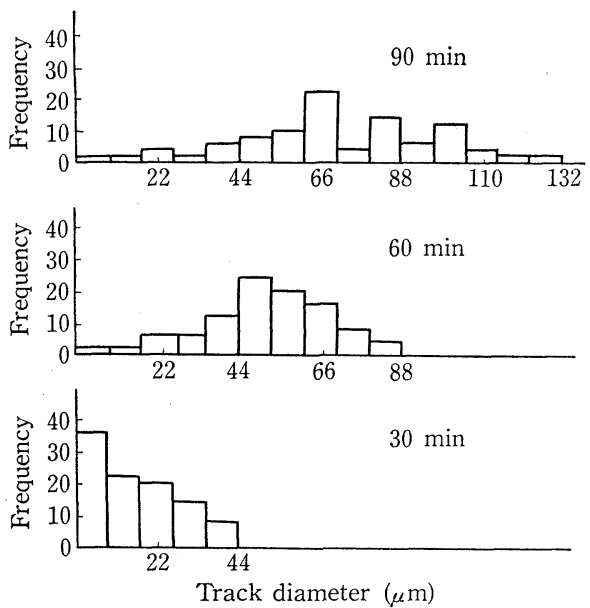

Fig. 5 Relative track diameter distribution of 5.05 $\mathrm{MeV}$ alpha particles for different etching time under standard etching condition.

minutes of etching, the Bragg peak begins to appear near the surface. Ninety-five percent of the tracks occur with a diameter less than $17.6 \mu \mathrm{m}$. Figure 5 is a typical track diameter distribution for high energy charged particles. The Bragg peak is still far in the deep layer of the foil. So the track diameter distribution almost covers the whole range from 0 up to $132 \mu \mathrm{m}$.

The most important result of the present work concerns the feasibility of $\alpha$ track registration in the

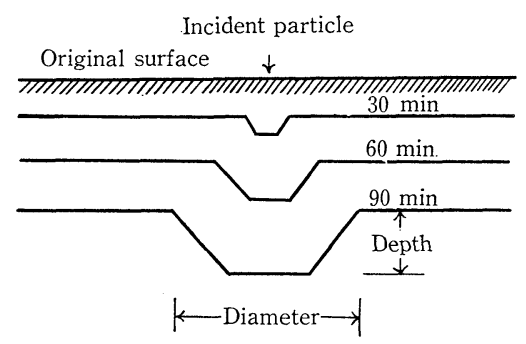

Fig. 6 Track diameter increased with etching time.

polycarbonate foil using ECE. It was experimently shown that there is a maximum track efficiency which occurs at rather low energy and decreases by as much as two orders of magnitude toward higher energies.

From this study on the relative frequency of track diameter distributions it is evident that the track diameter depends on the latent track position in the polycarbonate foil. As etching time goes on, the existing track of the high energy $\alpha$ increases its track diameter as Fig. 6 shows, and at the same time some tiny tracks begin to appear if the range of the charged particle is greater than the surface layer removed.

\section{REFERENCES}

1) D.A. Young; Etching of radiation damage in lithium fluoride, Nature, 182, 375 (1958).

2) P.B. PRICE and R.M. WALKER; Electron microscope observation of etched tracks from spallation recoils in mica, Phys. Rev. Lett., 8, 217 (1962).

3) R.L. FLeISCHER and P.B. PRICE; Tracks of charged particles in high polymers, Science, 140, 1221 (1963).

4) R.L. Fleischer, P.B. Price and R.M. Walker; Tracks of charged particles in solids, Science, 149, 383 (1965).

5) R.L. Fleischer, P.B. Price and R.M. Walker; "Nuclear Tracks in Solids," University of California Press, Berkeley, California (1975).

6) L. Tommasino and C. Armellini; New etching technique for damaged track detectors, Radiat. Eff., 20, 235 (1970).

7) M. Sohrabi; The applification of recoil particle tracks in fast neutron personnel dosimetry, Health Phys., 27, 498 (1974).

8) M. Sohrabi and K.Z. Morgan; Neutron Dosimetry in High Energy X-ray Beams of Medical Accelerators, Phys. Med. Biol., 24, 1 (1979).

9) S.J. Cotter, R.B. Gammage, J.H. Thorngate and P.L. ZIMMER; Comparison of fast neutron-induced 
tracks in plastics using the electrochemical etching method," Health Phys., 37, 365 (1979).

10) S.J. Su; "Neutron dosimetry using electrochemi- cal etching," Ph.D. Thesis, Georgia Institute of Technology, Ga. (1979). 